\title{
Influence of Sociocultural Factors in the Development of Mental Illness and its Treatment: About a Clinical Case in Ouagadougou, Burkina Faso
} Nanéma D*, Goumbri P, Karfo K, Zika O, Ouango J and Ouédraogo A

University Hospital Yalgado Ouédraogo, 03 BP 7177 Ouagadougou, Burkina Faso

\begin{abstract}
The origin of mental illness can be multifactorial, influencing the therapeutic route and treatment delays. We report in this paper the case of Miss B.D., young woman that, under the influence of multiple stress factors, and various conceptions of the disease, developed a table of severe depression with psychotic symptoms, the waning of hypertensive nephropathy. Despite the evidence brought by modern medicine in the treatment of such disorders (organic and psychiatric), distrust of administered therapeutics was observed with the addition of traditional and magical-religious treatment. This case illustrates the need to develop liaison psychiatry, to conduct information and awareness campaigns on mental illness and its treatment with the population of Burkina Faso.
\end{abstract}

Keywords: Sociocultural factors; Depression; Hypertensive nephropathy; CHUYO-Burkina Faso

\section{Introduction}

Several years have passed since psychiatry, as a medical science, has moved away from magical-religious concepts in developed countries, and acquired in these countries, a rational explanation [1-3]. In Africa, disease in general, and in particular mental illness has several causes, with an important place given to mystical-religious ideas [4-11]. A series of social factors can influence the onset, course and outcome of organic but also mental disorders. Indeed, tradition that still holds a considerable weight in our African societies, with its concepts, greatly influences the choice of treatment [5]. Therapeutic recourses are multiple, starting mostly with traditional therapy, often combined with modern treatment and finishing mostly with the traditional therapist, the marabout, the pastor or the priest $[6,9,11]$.

These beliefs and attitudes of society determine many aspects of mental health care and help define the therapeutic route of the patient, which is an important step to be taken into account in care management [8-11]. In the case of mental illness in Africa, the therapeutic route seems special because of false and stubborn social prejudices erected in true line of conduct $[9,11]$.

The family in the broader sense plays a very important role in the course of treatment $[6,9]$ and concepts and practices often contribute to the emergence of somatic diseases which, if they are not treated in a spirit of pluri-disciplinarity, can lead to mental illness [1]. We report the case of Miss B.D., whose story deserves to be told for many reasons. From its clinical observation and personal history, we will draw in this work some reflections on the influence of traditional concepts of illness and their consequences on the psychopathology of some mental illnesses such as depression.

\section{Clinical Case}

Miss B. D. is a young lady that was 31 years old when she was admitted to hospital at the Psychiatry ward of the university hospital yalgado ouedraogo (CHUYO) in April 2011. She was conducted by her father, mother and aunt, for disorders of behavioral type such as runaway attempts, physical and verbal aggression and insomnia lasting for several months. The questioning reveals that this episode had evolved in recent days, marked by total insomnia, delirium of persecution with an interpretative mechanism against her family and a mystical-religious delirium. Drug therapy based on amitriptyline tablet, haloperidol tablets and lorazepam tablets had been administered, together with a traditional treatment with fumigations, which did not improve the clinical picture. Examination at the entrance found a delirious disorder and a depressive syndrome. An assumption of severe depression with psychotic features was stated.

Miss B. D. is the mother of a four-years-old girl. She had been living in free-union since 1998. Her health problems had started when she was pregnant, exactly at seven months of pregnancy, marked by insomnia by early onset of sleep and early awakenings. Palpitations occurred, allegedly associated with the clinical picture during the night after the religious wedding ceremony of her brother-in law, younger than her partner. This symptomatology had benefited from treatment by traditional therapy including concoctions to drink and to wash and sacrifices and "Douas " to perform, that had presumably improved the clinical picture.

Two months later, she had preeclampsia with expulsion of a stillborn boy in a local medical centre with surgical antenna (CMA), from which she had been referred to the renal-dialysis ward of the CHUYO.

She stayed there for about 21 days but the nature of the therapeutic treatment has not been found. She confesses that during her hospitalization, recriminations and ill-treatment by her parents against her partner, especially by her maternal grandmother, were administered. The latter accused her partner of being the basis of all this and accused him of being cannibalistic sorcerer. It is on this background of conflict between the partner and in-laws, that when leaving the hospital, she was taken to her maternal grandparents' for convalescence. For her, the smear campaign against her companion had continued, and with the intervention of the "gansoaba", the patriarch the husband's family

*Corresponding author: Nanéma D, BP 7177 Ouagadougou, Burkina Faso, Tel: (+226) 703235 30; E-mail: desenanem@yahoo.fr

Received: February 08, 2016; Accepted: February 16, 2016; Published: February 23, 2016

Citation: Nanéma D, Goumbri P, Karfo K, Zika O, Ouango J, et al. (2016) Influence of Sociocultural Factors in the Development of Mental Illness and its Treatment: About a Clinical Case in Ouagadougou, Burkina Faso. Clin Depress 2: 108.

Copyright: () 2016 Nanéma D, et al. This is an open-access article distributed under the terms of the Creative Commons Attribution License, which permits unrestricted use, distribution, and reproduction in any medium, provided the original author and source are credited. 
went to ask for the hand of the woman, she had returned to the marital home. She had made two suicide attempts by ingestion of common medications in November 2011, with a formal observation stay of a day at medical emergencies of CHU-YO, and she was put under dipotassium clorazepate $10 \mathrm{mg}$ capsules with a psychiatric consultation with the parents but they did not come. At the family level, there is no psychiatric history. Miss B. D. comes from a monogamous family, the father is a superior telecommunications technician and the mother is an accountant; she is the first in a family of four children. Her father describes her as a child without problems. She has a D baccalaureate diploma and a university diploma of technology (DUT) in banking. She is from Mossi culture, Yadega, Muslim at birth. For the father, his wife's family is responsible for the condition of her daughter.

The treatment consisted in prescribing antipsychotics (haloperidol), antidepressants (paroxetine), lorazepam, supportive psycho-therapy, and family interviews that helped revive the dialogue between wife's family and partner.

The outcome was favorable and she came out after a 36-days stay in hospital under Risperidone and Paroxetine. She returned to her husband's home, and can manage to conduct most of her housework chores. Her father received at an interview in November 2011 admits that with his mother since her leaving the hospital, in addition to the treatment of the hospital, they continue other treatments. He says it is his wife who turns to look for the origin of the disease: "Currently, we use a traditional therapist at the village, who was crazy, who wandered for more than seven years in the bush of Banfora. He is healed and now cures cases. He gives sacrifices to the sacred crocodiles, but he told us to continue with the treatment prescribed in psychiatry. His treatment takes time. In sacrifices, chickens, sheep, and oxen, it took us more than three to four million CFA francs".

As for the patient, it is especially in the Protestant and charismatic prayers that she goes. The patient was lost from sight since December 2011.

\section{Discussion}

Health according to the WHO is a state of complete physical, mental and social well-being and not merely the absence of disease or infirmity [1]. The origin of disease may be multifactorial [1-3,5]. Although this observation alone does not allow general considerations, it allows us to draw important information. Indeed, according to beliefs and societies, nothing happens at random in this world and everything has an explanation.

Thus, this patient, after seven months of pregnancy, taking a talisman "liulgou " and other concoctions to protect herself and her pregnancy with the help of her mother, had contributed to cause this preeclampsia, with corollaries such as the loss of her baby and hypertensive nephropathy. Support after the loss of the baby and hospitalization in nephrology were not global. Treatment in early psychological care would certainly have helped understand the problem and propose solutions and adequate support. The tear perceived when she was still in hospital vis-à-vis the smear campaign against her companion and her in-laws, undertaken by her maternal grandparents and continued after discharge from hospital will certainly have been the straw that broke the camel's back.

This clinical case demonstrates the need for a frank collaboration between on the one hand health services, and secondly, the need for global care and management for patients in our hospitals. It also raises the question about the concepts and beliefs that the patients have on themselves and on their families, on psychiatric services, concepts that play an important role in the consultation delays [5,7,9-11]. Indeed, after the attempted suicide in November 2010, a psychiatric consultation form in due form was delivered to the family, who preferred turning to traditional treatments.

In Africa, several authors have defined the existence of a "plurality of causes" of disease, that is to say, the possibility to discuss several causes for the same disease [4-11]. Despite the poor results recorded largely for traditional healers, this route remains essential for families $[5,9,11]$. They are driven by the persistence of traditional culture but also by secular interpretative approaches to disease and mental illness in particular [4-11]. For Ouango JG, using the example of madness, he believes that the therapeutic itinerary of the crazy when coming through the psychiatric services, starts and always ends with the healer, who knows, hears and knows the invisible world, responsible for disease and healing [11]. Thus, modern medicine, Whiteman medicine, for both organic diseases and mental illness, seems to exist for calming emergencies, in order to enable 'real therapists" to act [11]. For JG Ouango, what is required from the psychiatrist and collaborators is to calm the agitation, reduce aggression and improve mood with effective drugs known to perform it [11]. This could explain this constant search that the family makes around traditional healers, the prayers of deliverance and multiple sacrifices, despite the evidence provided by modern medicine in the treatment of psychiatric disorders. For Veyrie N, ethno-psychiatrist, all thoughts on disease, whether African, Asian or Pacific resorts to the same great principle: the attribution of intentionality to the invisible: a god, a spirit, an ancestor, a guardian spirit [5]. For Houngbe E and J and contributors in Benin, the concept of disease in African cultural background distinguished:

1. The so-called natural disease that is innate, acquired, an expression of God's will;

2. Provoked disease, which is caused by the action of a third party, often a cannibalistic sorcerer or a caster of spells or an ancestral spirit or a genius;

3. And disease by transgression, mainly the transgression of certain taboos responsible for serious diseases to both the subject and the community [7].

These conceptions justify the therapeutic itinerary of patients in general and especially the mentally ill. Treatment begins and ends with the traditional therapist, pastor or priest. This is the case of Miss B. D. and her family since her hospital discharge, in addition to drug therapy (neuroleptics, antidepressants) she follows the issue of prayer sessions with pastors and priests, while her parents work with traditional healers and other oracles and marabouts for the cause of the illness of their daughter and her destiny. This raises the problem of medium and longterm prognosis in the management of this patient. Indeed, depression with psychotic features has a high potential for relapse and recurrence $[2,3]$. This suggests the need for a real work of information, education and counseling in the family and society. In health structures, measures to promote a comprehensive care of patients should be undertaken, highlighting the role of psychological support, which has always been neglected at the expense of drug treatment. At the community level, awareness campaigns on mental illness and collaboration with other informal actors (traditional healers, priors, marabouts) are expected to reduce delays in consultation and treatment in specialized care structures and certainly help simplify therapeutic routes.

\section{Conclusion}

In our African societies, the influence of traditional concepts is always great. If certain conceptions and practices have proved their 
Citation: Nanéma D, Goumbri P, Karfo K, Zika O, Ouango J, et al. (2016) Influence of Sociocultural Factors in the Development of Mental Illness and its Treatment: About a Clinical Case in Ouagadougou, Burkina Faso. Clin Depress 2: 108.

Page 3 of 3

effectiveness, others, on the contrary, participate in promoting the emergence of organic and somatic diseases.

In our hospitals, a failure in the management of certain organic diseases can also lead to mental illness. This case illustrates the need for a real collaborative work through liaison psychiatry in our hospitals, who would participate in a global care of hospitalized patients. It is also necessary that the psychiatric department conducts awareness campaigns among the population on mental health and collaboration with traditional healers.

\section{References}

1. OMS (2001) Rapport sur la santé dans le monde.

2. Guelfi JD, Rouillon F (2007) Manuel de Psychiatrie.

3. Lempérieure T, Féline A, Adès J, Hardy P, Rouillon F (2006) Psychiatrie de l'adulte.
4. Collomb H (1965) Assistance psychiatrique en Afrique (expérience sénégalaise). Psychopathologie Africaine 1: 1-84.

5. Veyrie N (2003) la maladie psychiatrique en Afrique. Devenir 17: 231-245

6. Dozon JP, Sindzingré N (1986) pluralisme thérapeutique et médecine traditionnelle en Afrique contemporaine.

7. Houngbe EJ, Gandaho P, Agossou T, Ahyi RG (1997) Concept de la maladie mort et santé mentale dans l'aire culturelle adja-fon. Le Benin Médical 6:8-11.

8. Joly P. Représentations culturelles, itinéraires thérapeutiques et santé mentale infantile en Guadeloupe.

9. Karfo K, Ouango JG (2009) itinéraire thérapeutique de la maladie mentale en Afrique : le cas de la schizophrénie au Burkina Faso. PSY-CAUSE 53:21-25.

10. Lallemant M, Gonzague J, Gruenais M (1999) itinéraires et prise en charge thérapeutique à Brazzaville : la logique des choix Paris.

11. Ouango JG, Kéré M, Ouédraogo M, Kabore G (1998) Concept traditionnel et difficultés thérapeutiques psychiatriques de la folie chez les Moose du Kadiogo, Burkina Faso. Santé mentale au Québec 2: 197-211.
Citation: Nanéma D, Goumbri P, Karfo K, Zika O, Ouango J, et al. (2016) Influence of Sociocultural Factors in the Development of Mental Illness and its Treatment: About a Clinical Case in Ouagadougou, Burkina Faso. Clin Depress 2: 108.

\section{OMICS International: Publication Benefits \& Features}

\section{Unique features:}

Increased global visibility of articles through worldwide distribution and indexing

- Showcasing recent research output in a timely and updated manner

- Special issues on the current trends of scientific research

Special features:

- 700 Open Access Journals

50,000 editorial tean

- Rapid review process

Quality and quick editorial, review and publication processing

- Indexing at PubMed (partial), Scopus, EBSCO, Index Copernicus and Google Scholar etc

- Sharing Option: Social Networking Enabled

- Authors, Reviewers and Editors rewarded with online Scientific Credits

- Better discount for your subsequent articles

Submit your manuscript at: www.omicsonline.org/submission/ 